\title{
Differential expression of the integrin subunits in human fetal membranes
}

\author{
T. M. Malak and S. C. Bell ${ }^{*}$ \\ Department of Obstetrics and Gynaecology. The Medical School, University of Leicester, \\ Leicester LE2 7LX, UK
}

\begin{abstract}
The distribution of the $\alpha_{1}, \alpha_{3}-\alpha_{6}, \beta_{1}, \beta_{3}$ and $\beta_{4}$ integrin subunits in fetal membranes at term was examined using an indirect immunofluorescence technique and confocal laser scanning microscopy. In the amniotic epithelium, $\beta_{4}$ integrin $\left(\alpha_{6} \beta_{4}\right)$ exhibited distinct basal localization, whereas $\beta_{1}$ integrins $\left(\alpha_{3} \beta_{1}, \alpha_{5} \beta_{1}\right)$ were localized basolaterally. This finding suggests that integrins, especially $\alpha_{6} \beta_{4}$ which is a structural component of the hemidesmosomes, may function as basement membrane receptors. Integrins localized laterally may play a role in cell-cell interactions. $\beta_{1}\left(\alpha_{1} \beta_{1}, \alpha_{5} \beta_{1}\right)$ integrins are probably involved in cell-matrix interactions in the connective tissue layers which are rich in collagens and fibronectin. Cytotrophoblasts, located predominantly towards the chorionic basement membrane, mainly expressed $\alpha_{6} \beta_{4}$, while those located predominantly in the vicinity of decidua expressed $\alpha_{5} \beta_{1}, \alpha_{3} \beta_{1}$ and $\alpha_{1} \beta_{1}$. Decidual cells expressed $\alpha_{3} \beta_{1}$ and $\alpha_{1} \beta_{1}$, whereas $\alpha_{1}, \alpha_{5}, \alpha_{6}$ $\beta_{1}$ and $\beta_{4}$ were expressed in blood vessels. This pattern of integrin expression reflects the reported difference in composition of the extracellular matrix at these locations and obviates an important role for $\alpha_{5} \beta_{1}$ at the chorio-decidual interface. The differential integrin expression at the cell-basement membrane interfaces demonstrated in this study (at amniotic epithelium, cytotrophoblasts, decidual cells and blood vessels) indicated a differential recognition of basement membranes by these cells. $\beta_{4}$ may have a specialized function at the blood vessels, and possibly in cytotrophoblasts, that is distinct from its role in hemidesmosome-mediated attachment. This study suggests that integrins may be involved in cell-matrix and cell-cell adhesions in fetal membranes and may therefore be important for maintaining their normal structural and functional integrity.
\end{abstract}

\section{Introduction}

The normal development, structure and function of fetal membranes (amniochorion and decidua) are very important for normal progress and outcome of human pregnancy (Malak and Bell, 1993). Fetal membrane dysfunction may lead, for example, to their prelabour rupture, a condition that is associated with a high risk of maternal morbidity, preterm birth and neonatal morbidity and mortality (Alger and Pupkin, 1986).

Fetal membranes are composed of a cellular component and a complex and extensive extracellular matrix (ECM). The cellular component is mainly of epithelial (amniotic epithelium and cytotrophoblasts) or mesenchymal origin (for example, fibroblasts, myofibroblasts, decidual cells). The ECM is composed of collagens (for example, I, III and IV), non-collagenous glycoproteins (for example, fibronectin) and laminin (Aplin and Campbell, 1985; Aplin et al., 1985; Klima and Schmidt, 1988; Malak et al., 1993) and proteoglycans. The ECM plays an important role in regulating cell function, tissue development

*Correspondence and reprint requests.

Received 14 February 1994. during normal intra- and extra-uterine morphogenesis and in reparative processes (Hay, 1973, 1989). In fetal membranes, the ECM has a pivotal role in maintaining their normal structure and function (Artal et al., 1976).

Integrins, a family of transmembrane protein receptors composed of non-covalently linked $\alpha$ and $\beta$ subunits, play an important role in the interactions between cells and their ECM (Hynes, 1992). There are several integrin subfamilies, each with two to nine $\alpha$ subunits and a commonly shared $\beta$ subunit (Hynes, 1992). The detection of the $\alpha_{1}, \alpha_{3}$ or $\alpha_{5}$ integrin subunits in colocalization with $\beta_{1}$ implies the presence of the corresponding heterodimer receptors; $\alpha_{1} \beta_{1}, \alpha_{3} \beta_{1}$ and $\alpha_{5} \beta_{1}$, respectively (Korhonen et al., 1991; Hynes, 1992). Other $\alpha$ subunits can interact with more than one $\beta$ subunit, for example, $\alpha_{6} \beta_{1}$ and $\alpha_{6} \beta_{4}$. Integrins are involved in anchoring cells to the ECM and each $\alpha \beta$ receptor recognizes one or more extracellular ligand (Hynes, 1992). Integrins are also involved in modulating cellular activities by transmitting signals into and out of cells (Hynes, 1992), organization of the cytoskeleton (Akiyama et al., 1989) and ECM (Darribere et al., 1990) and in mediating important cell-cell interactions (Hynes, 1992). It has been reported that integrins may add to the cohesive strength necessary for the stationary epithelial sheet to remain intact 
Table 1. Monocloncal antibodies used in this study

\begin{tabular}{|c|c|c|c|c|c|}
\hline Primary antibody & Specificity & Immunized animal & IgG isotypes & IgG isotype $\left(\mu \mathrm{g} \mathrm{ml}^{-1}\right)$ & Source \\
\hline 102DF5 & $\beta_{1}$ & Mouse & $\lg G 1$ & 62.0 & Ylanne and Virtanen (1989) \\
\hline $3 \mathrm{E} I \mathrm{I}$ & $\beta_{4}$ & Mouse & IgG1 & 2.80 & Bioquote, York \\
\hline $\mathrm{TS} 2 / 7$ & $\alpha_{1}$ & Mouse & $\operatorname{IgG} 1$ & 4.70 & Hemler et al. (1984) \\
\hline P1B5 & $\alpha_{3}$ & Mouse & $\operatorname{lgG} 1$ & 3.70 & Bioquote, York \\
\hline $\mathrm{GoH} 3$ & $\alpha_{6}$ & Rat & $\operatorname{IgG} 2 a$ & ND & Sonnenberg et al. (1987) \\
\hline INN-hPRL-3 & Human prolactin & Mouse & $\lg G 3$ & 4.00 & Serotec, Oxford \\
\hline
\end{tabular}

ND: not determined (used as undiluted culture supernatant).

under the effect of stretch (Larjava, 1991). The fetal membranes, including their epithelial sheets (amniotic and cytotrophoblast), stretch to double their post-delivery surface area to cope with uterine growth (Parry-Jones and Priya, 1976). It is to be anticipated, therefore, that integrins would be essential for maintaining the integrity of the fetal membranes. It has been reported that $\alpha_{6}$ and $\beta_{4}$ may be involved in amniotic epithelium and trophoblast interactions with the ECM (Behzad et al., 1991; Aplin, 1993).

To understand the possible role of different integrins in the fetal membranes, we examined the distribution of $\alpha_{1}, \alpha_{3}-\alpha_{6^{\prime}} \beta_{1^{\prime}}$ $\beta_{3}$ and $\beta_{4}$ integrin subunits in fetal membranes at term with an indirect immunofluorescence technique and confocal laser scanning microscopy. The latter allows more precise localization of membrane proteins since it produces images in which out-offocus blur is essentially absent and, therefore, offers improved optical resolution and contrast (White et al., 1987).

\section{Materials and Methods}

This study was approved by the Ethical Committee of Leicestershire Health Authority.

\section{Tissues}

Fetal membranes (amniochorion and the attached decidua) were obtained immediately after normal term, vaginal deliveries. The membranes were examined to exclude any with extensive tearing, separation of their layers and clinical signs of infection. Two long strips of the fetal membranes extending from the rupture site to the placental edge were obtained. Polymorphonuclear infiltration was used as an indicator of infection (Salafia et al., 1989). Multiple specimens from 10 fetal membranes were included in this study. Specimens, taken from half-way between the rupture site and the site of placental attachment, were washed briefly in Tris-buffered saline, pH 7.6. Strips of the fetal membranes were rolled up with the amnion innermost, immediately frozen in liquid hexane and dry ice mixture $\left(-70^{\circ} \mathrm{C}\right)$ and stored at $-80^{\circ} \mathrm{C}$ until used. Additional specimens were fixed in $3 \%$ glutaraldehyde.

\section{Antibodies and immunoglobulin}

Monoclonal antibodies against integrin subunits were obtained commercially or as gifts (Table 1). Non-specific binding of the integrin antibodies was detected by staining control tissue sections with $\operatorname{IgG}$ at a concentration similar to that of IgG of the integrin antibodies. Purified mouse $\operatorname{IgG}$ (Sigma, Poole, Dorset) and anti-human prolactin antibody (used as a source for $\mathrm{IgG} 3$ ) were used.

Secondary antibodies (ICN Immunobiologicals, Thame, Bucks) were conjugated to fluorescein isothiocyanate. The working dilution was $1 / 500$. To reduce non-specific binding of the secondary antibodies, normal serum (diluted 1/20) obtained from the animal species used to raise their secondary antibodies was included in the primary antibody preparation. Non-specific binding of the secondary antibodies was detected by staining control tissue sections with Tris-buffered saline instead of the integrin antibodies.

\section{Indirect immunofluorescence microscopy}

Cryostat sections were cut at a thickness of $10-12 \mu \mathrm{m}$ and fixed in acetone at $-20^{\circ} \mathrm{C}$ for $5 \mathrm{~min}$. Autofluorescence was quenched by using $0.25 \mathrm{~mol}$ L-lysine $\mathrm{l}^{-1}$ at $4^{\circ} \mathrm{C}$ for $60 \mathrm{~min}$. Tissue sections were incubated with the primary antibodies at $37^{\circ} \mathrm{C}$ for $60 \mathrm{~min}$ and, subsequently, to the appropriate secondary antibodies at $37^{\circ} \mathrm{C}$ for $30 \mathrm{~min}$. Control sections were treated in the same way, except that primary integrin antibodies were replaced with purified IgG diluted in Tris-buffered saline, antibody against human prolactin or Tris-buffered saline. The tissue sections were examined using a confocal laser (argon ion) scanning microscope (Lasersharp MRC 600, Bio-Rad, Microscience Ltd, Hemel Hempstead, Herts). Images were obtained as single optical sections of the tissue preparation using a single channel fluorescence mode. The signals were collected over three frames using a real-time integration filter (Kalman filter) to remove photon noise.

Sequential cryostat tissue sections were stained with haematoxylin and eosin. Glutaraldehyde-fixed specimens were processed and embedded in Araldite and tissue sections ( $\mathrm{I} \mu \mathrm{m}$ thick) were stained with alkaline toluidine blue solution (Malak et al., 1993). 


\section{Results}

\section{Amniotic epithelium and its basement membrane}

The amniotic epithelium was represented by a single layer of apparently simple, non-ciliated cuboidal cells (Fig. 1). The basement membrane appeared as a narrow band lying along the base of the amniotic epithelium.

Integrin subunits $\beta_{1}, \alpha_{5}$ and $\alpha_{3}$ were basolaterally distributed in the amniotic epithelium (Fig. 2). The expression of $\alpha_{1}$ was non-polarized with basolateral and apical localization and was also found in the cytoplasm. $\beta_{4}$ was specifically localized to the basal surface of these cells and although $\alpha_{6}$ was also detected at highest intensity at this site, less immunoreactivity was detected in the basal part of their lateral surfaces (Fig. 3). The basal distribution of $\beta_{4}$ and $\alpha_{6}$ was punctate.

\section{Connective tissue}

The connective tissue layers of the fetal membranes (compact, fibroblast, spongy and reticular layers) were composed mainly of a fibrillar network. The compact layer was acellular while the fibroblast and reticular layers contained many cells and the spongy layer contained very few cells (Fig. 1).

The fibroblast and reticular layers contained cells which expressed mainly $\beta_{1}, \alpha_{5}$ and $\alpha_{1}$ and to a lesser degree $\alpha_{3}$ (Fig. 4). No immunoreactivity related to $\beta_{4}$ or $\alpha_{6}$ was detected in this layer (Fig. 5).

\section{Cytotrophoblast and its basement membrane}

The thickness of the cytotrophoblast layer was variable. Within the cytotrophoblast, a layer of tightly packed cells was detected that abutted onto the chorionic basement membrane and was of variable thickness. The intercellular spaces surrounding these cells were narrow, whereas the intercellular spaces of the cytotrophoblast located predominantly towards the decidua were wider (Fig. 1). In some sections, degenerate villi were found within the cytotrophoblast layer. These were surrounded by a basement membrane (apparent as a narrow dense eosinophilic band) and cytotrophoblast that were adhering tightly to each other.

The cytotrophoblast located predominately towards the chorionic basement membrane (Figs 4,5) and that surrounding the degenerate villi (not shown) exhibited an intense pericellular, punctate expression of $\beta_{4}$ and $\alpha_{6}$ (especially the basal

Fig. 1. (a) A transmitted light micrograph of a haematoxylin- and eosin-stained section of human fetal membrane. Scale bar represents $30 \mu \mathrm{m}$. (b) Diagrammatic representation of the layers of fetal membranes. (c) Toluidine blue-stained section of the cytotrophoblast layer (scale bar $=10 \mu \mathrm{m}$ ) showing the intercellular spaces between the basal and superficial cytotrophoblasts. AE: amniotic epithelium; ABM: amniotic basement membrane; BT: basal cytotrophoblasts (cells predominately located towards the basement membrane); $C$ : compact layer; CBM: chorionic basement membrane; D: decidua; F: fibroblast layer; R: reticular layer; S: spongy layer; ST: superficial cytotrophoblasts (cells predominantly located towards the decidua).
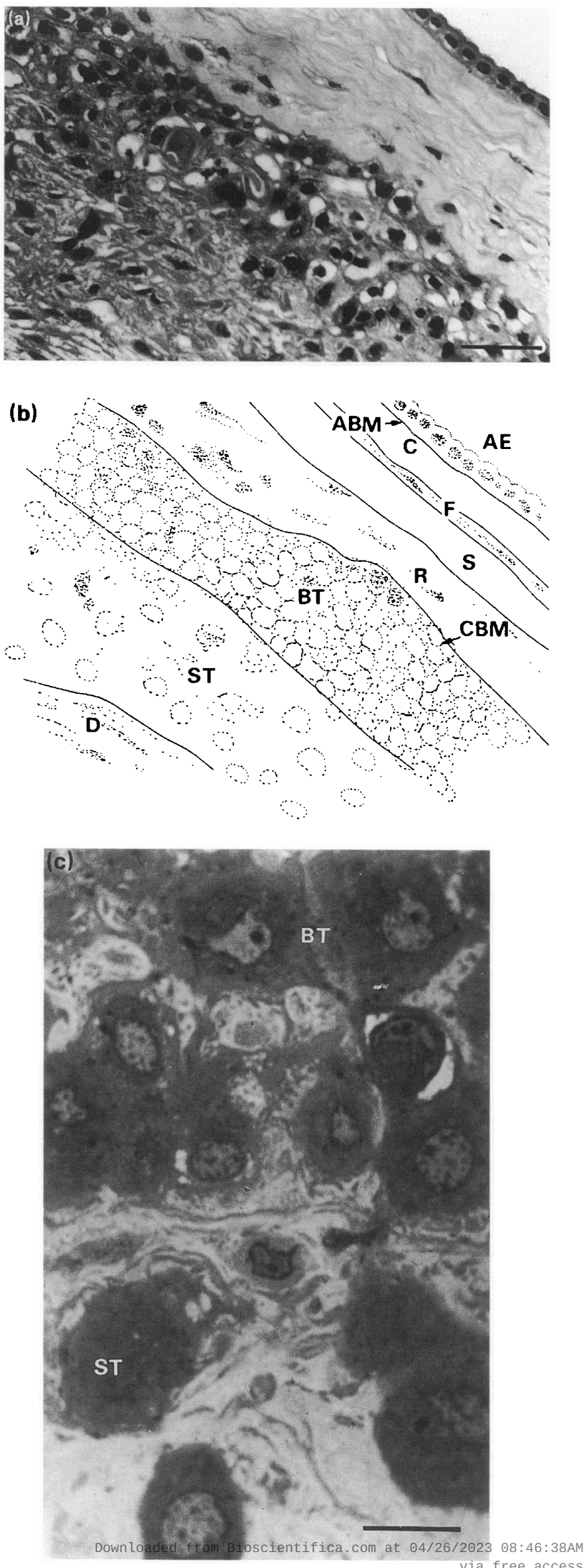

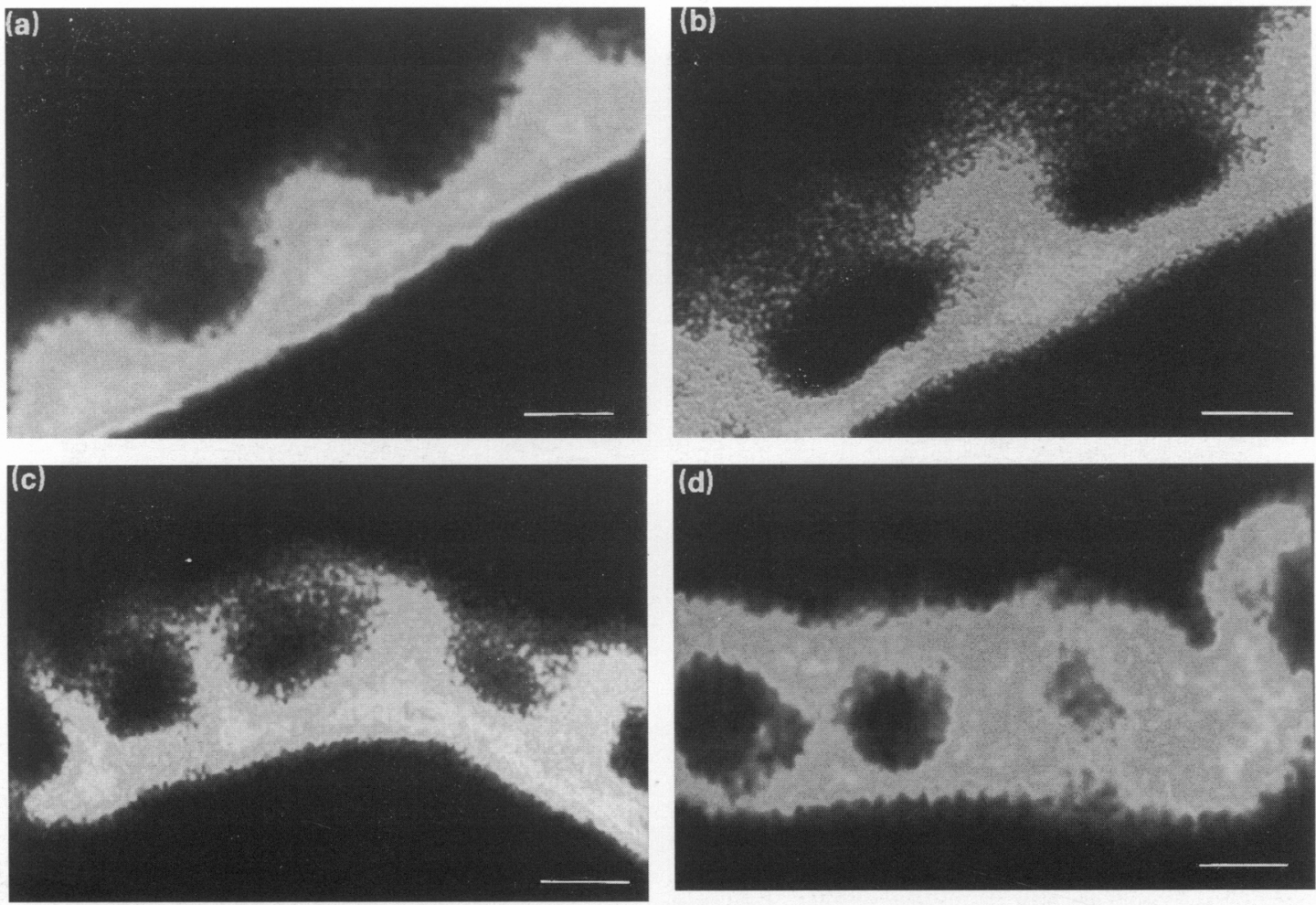

Fig. 2. A confocal indirect immunofluorescence micrograph of the distribution of (a) $\beta_{1}$, (b) $\alpha_{5}$, (c) $\alpha_{3}$ and (d) $\alpha_{1}$ integrin subunits in amniotic epithelium of human fetal membranes. Integrin subunits $\beta_{1}, \alpha_{5}$ and $\alpha_{3}$, were basolaterally expressed. The expression of $\alpha_{1}$ was non-polarized with basolateral and apical localization; it was also found in the cytoplasm. Scale bars represent $5 \mu \mathrm{m}$.

surface adjacent to the chorionic basement membrane) (Fig. 5). The punctate expression was less prominent than that in the amniotic epithelium. These cells were less intensely positive for $\beta_{1}$ and $\alpha_{3}$, faintly positive for $\alpha_{5}$ and mainly negative for $\alpha_{1}$ (Fig. 4). The cytotrophoblast located predominantly towards the decidua expressed $\beta_{1}, \alpha_{5}, \alpha_{3}$ and $\alpha_{1}$ (Fig. 4). but were less intensely positive for $\beta_{4}$ and $\alpha_{6}$ (Fig. 5).

\section{Decidua}

The decidual cells exhibited less dense eosinophilic cytoplasm and more regular nuclei than did the cytotrophoblast (Fig. 1). Decidual cells expressed $\beta_{1}, \alpha_{1}$ and $\alpha_{3}$. They were very faintly positive for $\alpha_{5}$ (Fig. 4) and negative for $\beta_{4}$ (Fig. 5). Immunoreactivity related to $\alpha_{6}$ was very faint and was detected only in some tissue sections.

Blood vessels of the decidua expressed high intensity $\beta_{4}$-related immunoreactivity, were less intensively positive for $\alpha_{1}, \alpha_{5}$ and $\beta_{1}$, faintly positive for $\alpha_{6}$ and negative for $\alpha_{3}$ (not shown)

No convincing immunoreactivity with anti- $\alpha_{4}$ and $-\beta_{3}$ could be detected in any layers of the fetal membranes. In control tissue sections, no staining was detected except a very faint staining of the amniotic epithelium with $\operatorname{IgGI}$ at concentrations of more than $46 \mu \mathrm{g} \mathrm{ml}^{-1}$. The distribution of integrin subunits in the various layers of the fetal membranes is shown (Table 2).

\section{Discussion}

In this study, we report the distribution of integrin subunits in human fetal membranes at term by indirect immunofluorescence, using antibodies against these subunits. However, the distribution of integrin heterodimer receptors can be inferred from such studies for two reasons. First, the individual $\alpha$ or $\beta$ subunits of integrins are not transported to the cell surface (Springer et al., 1987; Heino et al., 1989; Rosa and McEver, 1989) and second, the detection of the $\alpha_{1}, \alpha_{3}$ or $\alpha_{5}$ integrin subunits in colocalization with $\beta_{1}$ implies the presence of the corresponding heterodimer receptors: $\alpha_{1} \beta_{1}, \alpha_{3} \beta_{1}$ and $\alpha_{5} \beta_{1}$, respectively (Korhonen et al., 1991; Hynes, 1992). Integrin subunit $\alpha_{6}$ may form the heterodimers $\alpha_{6} \beta_{1}$ and $\alpha_{6} \beta_{4}$ with $\beta_{1}$ and $\beta_{4}$, respectively. However, immunoprecipitation experiments have suggested that $\alpha_{6} \beta_{4}$ is the major $\alpha_{6}$-containing complex on cells that express $\alpha_{6}, \beta_{1}$ and $\beta_{4}$ subunits (Hemler et al., 1989). Although the ECM ligands of most integrin receptors have been identified (Hemler et al, 1989 ), that of $\alpha_{6} \beta_{4}$ integrin has yet to be established. However, it may act as a laminin receptor (Lee et al., 1992).

The presence of integrins at cell-basement membrane interfaces and the presence of their ligands in the basement membrane may indicate that they function as basement membrane receptors (Korhonen et al., 1991). Integrin expression was different at the various cell-basement interfaces found in fetal membranes, that is, at the amniotic epithelium $\left(\alpha_{6} \beta_{4}, \alpha_{5} \beta_{1}\right.$, $\left.\alpha_{3} \beta_{1}\right)$, cytotrophoblast $\left(\alpha_{6} \beta_{4}\right.$ and to a lesser extent $\left.\alpha_{3} \beta_{1}\right)$, 

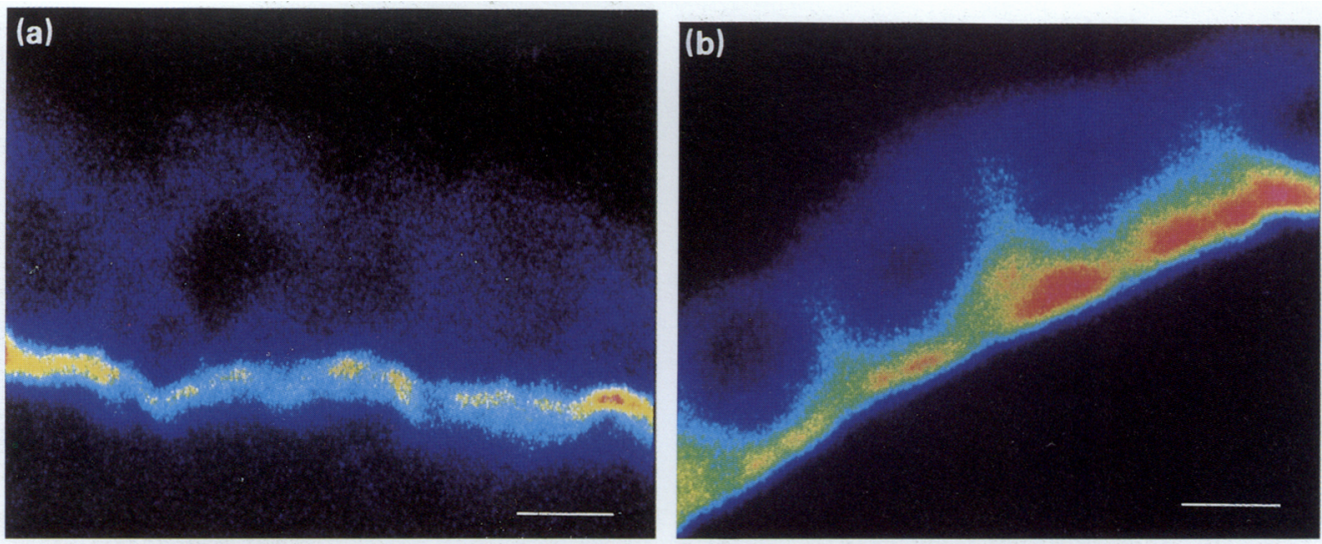

Fig. 3. A confocal indirect immunofluorescence micrograph of the distribution of (a) $\beta_{4}$ and (b) $\alpha_{c}$ integrin subunits in amniotic epithelium of human fetal membranes. $\beta_{4}$ was specifically localized to the basal surface of the epithelium and, although $\alpha_{c}$ was also detected at highest intensity at this site, less immunoreactivity was detected in the basal part of the lateral surfaces. Scale bars represent $5 \mu \mathrm{m}$. Pseudocolour intensities: white $>$ red $>$ yellow $>$ green $>$ blue (negative staining).
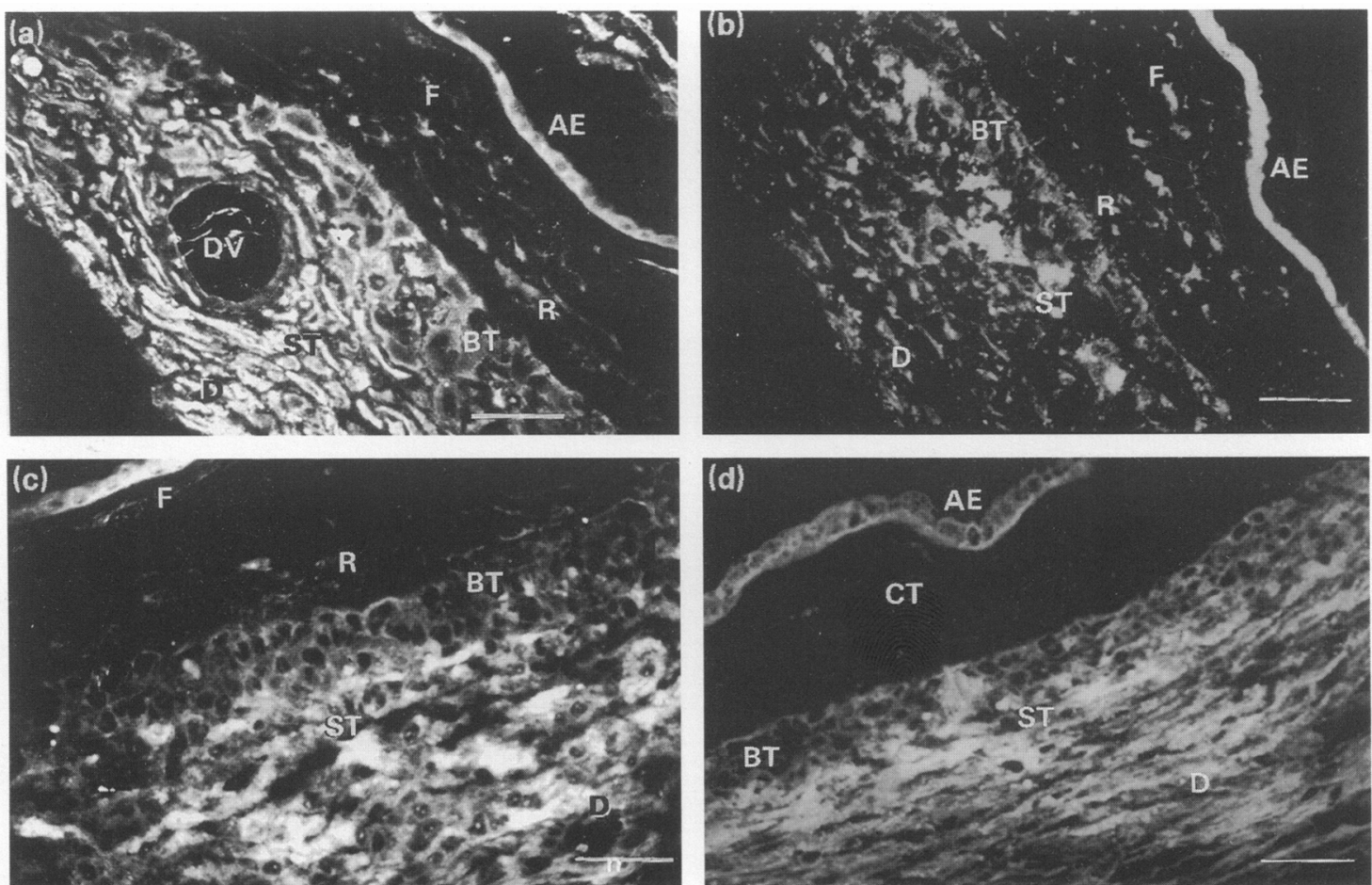

Fig. 4. A confocal indirect immunofluorescence micrograph of the distribution of (a) $\beta_{1}$, (b) $\alpha_{5}$, (c) $\alpha_{1}$ and (d) $\alpha_{3}$ integrin subunits in human fetal membranes. $\beta_{1}, \alpha_{5}, \alpha_{1}$, and to a lesser extent $\alpha_{3}$, were expressed in the connective tissue layers. The cytotrophoblasts located predominantly towards the basement membrane were positive for $\beta_{1}$ and $\alpha_{3}$ and faintly positive for $\alpha_{5}$ and $\alpha_{1}$. The cytotrophoblasts located predominantly towards the decidua expressed $\beta_{1}, \alpha_{5}, \alpha_{3}$ and $\alpha_{1}$. Decidual cells expressed $\beta_{1}, \alpha_{1}$ and $\alpha_{3}$ and were faintly positive for $\alpha_{5}$. Scale bars represent $50 \mu \mathrm{m}$. AE: amniotic epithelium; BT: basal cytotrophoblasts (cells located predominantly towards the basement membrane); CT: connective tissue; D: decidua; DV: degenerate villus; F: fibroblast layer; R: reticular layer; ST: superficial cytotrophoblasts (cells located predominantly towards the decidua).

decidual cells $\left(\alpha_{3} \beta_{1}, \alpha_{1} \beta_{1}\right)$ and decidual blood vessels $\left(\alpha_{6} \beta_{4}\right.$, $\left.\alpha_{5} \beta_{1}, \alpha_{3} \beta_{1}\right)$. This indicates that these cells may differentially recognize basement membrane components.

The presence of $\alpha_{6} \beta_{4}$ in the amniotic epithelium and cytotrophoblast is in agreement with other reports (Behzad et al., 1991; Aplin, 1993). The punctate expression of $\alpha_{0} \beta_{4}$ integrin indicates that it may be localized to well-defined structures. Indeed, $\alpha_{b} \beta_{4}$ has been reported to represent one of the two transmembrane proteins present in hemidesmosomes (Stepp et al., 1990). Hemidesmosomes mediate epithelial and 

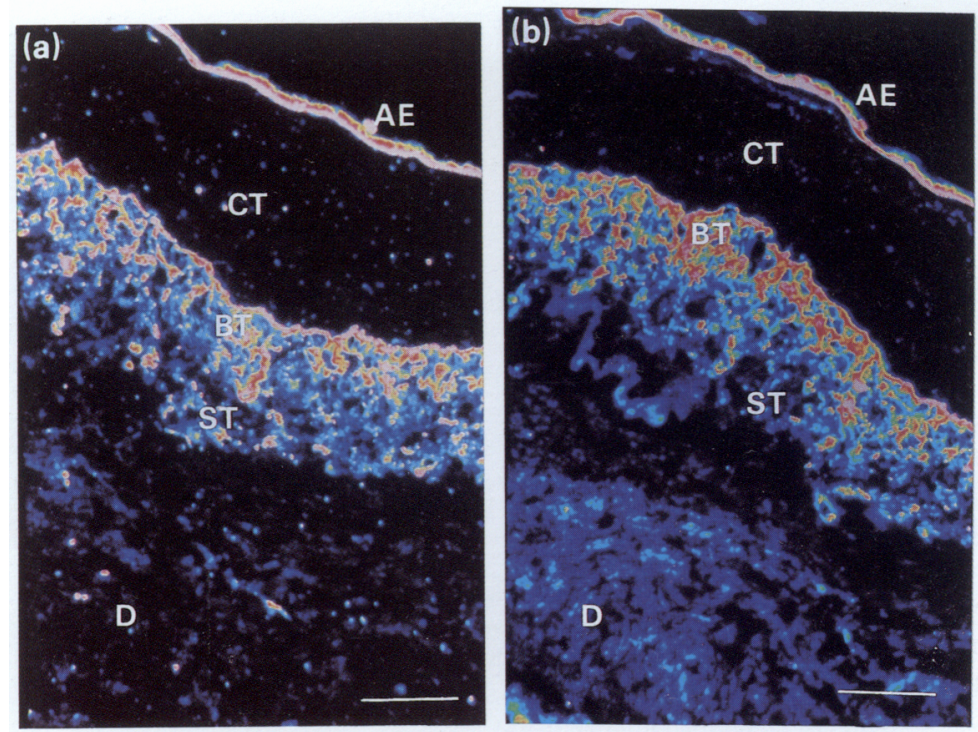

Fig. 5. A confocal indirect immunofluorescence micrograph of the distribution of (a) $\beta_{4}$ and (b) $\alpha_{6}$ integrin subunits in human fetal membranes. $\beta_{4}$ and $\alpha_{6}$ were negative in connective tissue and decidua. The cytotrophoblasts located predominantly towards the basement membrane exhibited an intense staining for $\beta_{4}$ and $\alpha_{6}$, but cells located predominantly towards the decidua were less intensely positive for $\beta_{4}$ and $\alpha_{0}$. Scale bars $=100 \mu \mathrm{m}$. AE: amniotic epithelium; BT: basal cytotrophoblasts (cells located predominantly towards the basement membrane); CT: connective tissue; D: decidua; ST: superficial cytotrophoblasts (cells located predominantly towards the decidua). Pseudocolour intensities: white $>$ red $>$ yellow $>$ green $>$ blue (negative staining).

Table 2. Distribution of integrin subunits in human fetal membranes (amniochorion and decidua)

\begin{tabular}{|c|c|c|c|c|c|c|c|c|}
\hline \multirow[b]{2}{*}{ Source } & \multirow[b]{2}{*}{$\alpha_{1}$} & \multirow[b]{2}{*}{$\alpha_{3}$} & \multicolumn{3}{|c|}{ Integrin subunit } & \multirow[b]{2}{*}{$\beta_{1}$} & \multirow[b]{2}{*}{$\beta_{3}$} & \multirow[b]{2}{*}{$\beta_{4}$} \\
\hline & & & $\alpha_{4}$ & $\alpha_{5}$ & $\alpha_{6}$ & & & \\
\hline Amniotic epithelium & $+{ }^{a}$ & $++^{b}$ & - & $+b$ & $+b$ & $+b$ & - & $+c$ \\
\hline Connective tissue cells & + & $-1+$ & - & + & - & + & - & - \\
\hline Basal cytotrophoblast & - & $-1+$ & - & $-1+$ & + & $-1+$ & - & + \\
\hline Superficial cytotrophoblast & + & + & - & + & $-1+$ & + & - & $-1+$ \\
\hline Decidual cells & + & + & - & $-1+$ & - & + & - & - \\
\hline
\end{tabular}

+ : intense immunoreactivity present; $-1+$ : less intense or equivocal immunoreactivity; - : no reactivity detected. ${ }^{a}$ Non-polarized expression; ${ }^{b}$ basolateral expression ( $\alpha_{6}$ is mainly basal); 'basal expression.

mesenchymal cell attachment to the underlying basal lamina and are found to be numerous along the basal surface of amniotic epithelium (Aplin et al., 1985; Malak et al., 1993). However, the presence of hemidesmosomes at the basal surface of fetal membrane cytotrophoblast is controversial (Wang and Schneider, 1983; Schmidt, 1992) and endothelial cells lack typical hemidesmosomes (Hieda et al., 1992). Therefore, the adhesive function of $\alpha_{6} \beta_{4}$ in blood vessels, and possibly in cytotrophoblasts, may be distinct from its role in hemidesmosome-mediated attachment. The exact localization of $\beta_{4}$ in the absence of hemidesmosomes remains to be determined.

The basal localization of $\beta_{1}\left(\alpha_{3} \beta_{1}, \alpha_{5} \beta_{1}\right)$ in the amniotic epithelium and pericellular localization of $\beta_{1}\left(\alpha_{3} \beta_{1}, \alpha_{1} \beta_{1}\right)$ integrins in decidual cells suggest that they may be used as basement membrane receptors at these sites. A similar role was described for $\beta_{1}\left(\alpha_{3} \beta_{1}, \alpha_{2} \beta_{1}\right)$ integrins in skin (Carter et al., $1990 \mathrm{a}, b)$. Recently, $\alpha_{5} \beta_{1}$ was found to be localized specifically to the basal membrane of the basal cells of the stratified squamous epithelium of the cornea (Stepp et al., 1993), suggesting that it may have a role in cell-basement membrane adhesion.

$\beta_{1}\left(\alpha_{3} \beta_{1}, \alpha_{5} \beta_{1}, \alpha_{6} \beta_{1}\right)$ integrins were laterally localized in the amniotic epithelium; however, their ECM ligands (fibronectin, laminin and collagens $I$ and VI) have not been detected in the amniotic cell-cell contact regions. This suggests that $\beta_{1}$ integrins may play a role in cell-cell interactions. Indeed, $\beta_{I}$ $\left(\alpha_{2} \beta_{1}, \alpha_{3} \beta_{1}\right)$ integrins have been found to be concentrated in cell-cell contacts of keratinocytes, where they perform a functional role in the maintenance of cell-cell interactions 
(Larjava et al., 1990; Marchisio et al., 1990; Carter et al., 1990b). The exact nature of this role is not fully characterized but it has been proposed (Larjava et al., 1990) that an unidentified ligand molecule mediates cell-cell adhesion indirectly by bridging integrin receptors located in two adhering cells. Alternatively, it may involve direct association of integrin dimers on adjacent cells (Larjava et al., 1990) or direct interaction of integrins with unidentified membrane co-receptors in adhering cells (Carter et al., 1990b).

Cells of the reticular and fibroblast layers expressed $\beta_{1}$ integrin similar to fibroblasts (Ylanne and Vitranen, 1989), smooth muscle cells (Belkin et al., 1990) and macrophages (Kohn and Klingemann, 1991). However, term placental villous stromal cells do not express $\beta_{1}$ (Korhonen et al., 1991), which may reflect different cellular populations or cell-matrix interactions in these sites. The ECM of the connective tissue contains collagens, laminin and fibronectin (Klima and Schmidt, 1988; Malak et al., 1993) which are known ligands for the $\beta_{1}$ $\left(\alpha_{1} \beta_{1}, \alpha_{5} \beta_{1}, \alpha_{3} \beta_{1}\right)$ integrins.

Within the cytotrophoblast layer, two subpopulations with distinctive patterns of integrin expression were detected. This integrin expression may reflect the reported difference in the composition of ECM surrounding these two cytotrophoblast subpopulations (Malak et al., 1993). The cytotrophoblast located predominantly towards the chorionic basement membrane expressed pericellular $\alpha_{6} \beta_{4}$ and to a lesser extent $\alpha_{3} \beta_{1}$ (collagens, fibronectin and laminin receptors). The ECM surrounding these cells is mainly composed of basal lamina-like material (Malak and Bell, 1994). It is stained positive for laminin, collagen IV and fibronectin (Aplin and Campbell, 1985; Klima and Schmidt, 1988; Malak et al., 1993) but it does not contain fibrillar collagens, for example, collagens I and III (Malak et al., 1993).

In contrast, the cytotrophoblast located predominantly towards the decidua expressed mainly $\alpha_{5} \beta_{1}$ (fibronectin receptor), $\alpha_{3} \beta_{1}$ and $\alpha_{1} \beta_{1}$ (laminin and collagens receptor) and less $\alpha_{6} \beta_{4}$. The ECM at this site contains fibrillar collagens (collagen III) (Malak et al., 1993), fibrillin-containing microfibrils and to a lesser extent basal-lamina-like material (Malak and Bell, 1994).

The pericellular expression of $\alpha_{6} \beta_{4}$ in cytotrophoblast may be an example of cell-matrix interactions that involve $\beta_{4}$ but are not hemidesmosome mediated. Hemidesmosomes have not been reported to mediate attachment of cytotrophoblasts to the ECM.

The intense expression of $\alpha_{5} \beta_{1}$ by the cytotrophoblast located near to the decidua is of interest. Although fibronectin, the $\alpha_{5} \beta_{1}$ ligand, is widely distributed in fetal membranes (Aplin and Campbell, 1985; Klima and Schmidt, 1988; Lockwood et al., 1991), $\alpha_{5} \beta_{1}$ expression follows most closely the distribution of the oncofetal isoform of fibronectin in the fetal membranes (Feinberg et al., 1991; Lockwood et al., 1991). Oncofetal fibronectin binds $\alpha_{4} \beta_{1}$ integrin via its alternatively spliced IIICS region; however, we did not detect $\alpha_{4}$ integrin subunit in the fetal membranes. This finding suggests that $\alpha_{5} \beta_{1}$ may function as a receptor for oncofetal fibronectin in fetal membranes. The presence of $\alpha_{5}$ and absence of $\alpha_{4}$ integrin subunits on cytotrophoblasts were also reported in normal human implantation sites (Korhonen et al., 1991; Damsky et al., 1992), where oncofetal fibronectin is localized to the ECM connecting extravillous cytotrophoblasts and cytotrophoblastic cell columns to the uterine decidua (Feinberg et al., 1991).

This difference in integrin receptors among the cells of the cytotrophoblast supports the previous histological and antigenic evidence for heterogeneity in the cytotrophoblastic layer of the fetal membranes (Bulmer and Johnson, 1985; Yeh et al., 1989; Malak et al., 1993). However, whether the two subpopulations, defined by differential integrin expression, correspond to the cytotrophoblast subpopulations defined histologically or antigenically, remains to be determined. The difference in integrin expression of the polarized cytotrophoblast $\left(\alpha_{6} \beta_{4}^{+}, \alpha_{3} \beta_{1}^{+{ }^{-}}\right)$and the non-polarized cells in the vicinity of decidua $\left(\alpha_{5} \beta_{1}{ }^{+}, \alpha_{1} \beta_{1}{ }^{+}, \alpha_{6} \beta_{4}^{+/-}\right)$is similar to the integrin expression of the polarized and non-polarized cytotrophoblast of the chorionic villi and was used as an indication of cytotrophoblast differentiation by Damsky et al. (1992), a process that may also occur in fetal membrane cytotrophoblast.

This study suggests that integrins are involved in cellmatrix and cell-cell interactions in fetal membranes, and may, therefore, play an important role in maintaining the normal structural and functional integrity and stability of these tissues. However, assays of function are needed to establish a complete understanding of the interactions occurring in integrin-mediated cell adhesion.

The authors are very grateful to WeliBeing, London and MRC for their generous support of this study.

\section{References}

Akiyama S, Yamada S, Chew W-T and Yamada K (1989) Analysis of fibronectin receptor function with monoclonal antibodies: roles in cell adhesion, migration, matrix assembly and cytoskeletal organization Joumal of Cell Biology $109863-869$

Alger LS and Pupkin MJ (1986) Etiology of preterm premature rupture of the membranes Clinical Obstetrics and Gynecology 29 758-770

Aplin JD (1993) Expression of integrin alpha 6 beta 4 in human trophoblast and its loss from extravillous cells Placenta 14 203-215

Aplin J and Campbell S (1985) An immunofluorescence study of extracellular matrix associated with the trophoblast of the chorion laeve Placenta 6 469-479

Aplin J, Campbell S and Allen T (1985) The extracellular matrix of human amniotic epithelium: ultrastructure, composition and deposition Journal of Cell Science 79 119-136

Artal R, Sokol R, Newman M, Burstein A and Stojkov J (1976) The mechanical properties of prematurely and nonprematurely ruptured membranes American Journal of Obstetrics and Gynecology 125 655-659

Behzad F, Jones CJ and Aplin JD (1991) The role of integrin alpha 6 beta 4 in hemidesmosomes of human amnion Biochemical Society Transactions $19381 \mathrm{~S}$ (Abstract)

Belkin V, Belkin A and Koteliansky V (1990) Human smooth muscle VLA-I integrin: purification, substrate specificity, localization in aorta and expression during development Journal of Cell Biology $1112159-2170$

Bulmer JN and Johnson PM (1985) Antigen expression by trophoblast populations in the human placenta and their possible immunobiological relevance Placenta 6 127-140

Carter W, Kaur P, Gil S, Gahr P and Wayner E (1990a) Distinct functions for integrins, $\alpha_{3} \beta_{1}$ in focal adhesions and $\alpha_{6} \beta_{4}$ /bullous Pemphigoid antigen in a new stable anchoring contact (SAC) of keratinocytes: relation to hemidesmosomes Journal of Cell Biology 111 3141-3154

Carter W, Wayner E, Bouchard T and Kaur P (1990b) The role of integrins $\alpha_{2} \beta_{1}$ and $\alpha_{3} \beta_{1}$ in cell-cell and cell substrate adhesion of human epidermal cells Journal of Cell Biology 110 1387-1404

Damsky CH, Fitzgeraid ML and Fisher SJ (1992) Distribution patterns of extracellular matrix components and adhesion receptors are intricately 
modulated during first trimester cytotrophoblast differentiation along the invasive pathway, in vivo Joumal of Clinical Investigations 89 210-222

Darribere T, Guida K, Larjava H, Johnson K, Yamada K, Thiery J-P and Boucaut J-C (1990) In vivo analyses of integrin $\beta_{1}$ subunit function in fibronectin matrix assembly journal of Cell Biology 110 1813-1819

Feinberg F, Kliman H and Lockwood C (1991) Is oncofetal fibronectin a trophoblast glue for human implantation? American Joumal of Pathology 138 $537-543$

Hay E (1973) Cell and extracellular matrix: their organization and mutual dependence Molecular and Cellular Biology 2 509-548

Hay E (1989) Extracellular matrix, cell skeleton and embryonic development American Journal of Medical Genetics 34 14-29

Heino J, Ignotz RA, Helmer ME, Crouse C and Massague J (1989) Regulation of cell adhesion receptors by transforming growth factor $\beta$. Concomitant regulation of integrins that share a common $\beta_{1}$ subunit joumal of Biological Chemistry 264 380-388

Hemler M, Sanchez-Madrid F, Flotte T, Krensky A, Burakoff S, Bhan A, Springer A and Strominger J (1984) Glycoproteins of 210000 and 130000 M.W. on activated T cells: cell distribution and antigenic relation to components on resting cells and $\mathrm{T}$ cell lines journal of Immunology 132 3011-3018

Hemler M, Huang C, Takada Y, Schwarz L, Strominger J and Clabby M (1987) Characterization of the cell surface heterodimer VLA-4 and related peptides Journal of Biological Chemistry 262 11478-11485

Hemler M. Crouse C and Sonnenberg A (1989) Association of the VLA $\alpha_{6}$ subunit with a novel protein Journal of Biological Chemistry 264 6529-6535

Hieda Y, Nishizawa Y, Uematsu J and Owaribe K (1992) Identification of a new hemidesmosomal protein, HD1: a major, high molecular mass component of isolated hemidesmosomes Journal of Cell Biology 116 1497-1506

Hynes RO (1992) Integrins: versatility, modulation, and signaling in cell adhesion Cell 69 11-25

Klima G and Schmidt W (1988) Immunohistochemical studies of the nature of connective tissue in fetal membranes Acta Histochemica 84 195-203

Kohn FR and Klingemann HG (1991) Regulation of fibronectin receptor (alpha 5 beta 1) mRNA expression in human monocytes and monocyte-derived macrophages by activation/differentiation signals Experimental Hematology $19653-658$

Korhonen M, Ylanne J, Laitinen L, Cooper HM, Quaranta V and Virtanen I (1991) Distribution of the $\alpha_{1}-\alpha_{6}$ integrin subunits in human developing and term placenta Laboratory Investigation 65 347-356

Larjava $\mathbf{H}$ (1991) Expression of beta 1 integrins in normal human keratinocyte American Journal of Medical Science 301 63-68

Larjava H, Peltonen J, Akiyama SK, Yamada SS, Gralnick HR, Uitto J and Yamada KM (1990) Novel function for beta 1 integrins in keratinocyte cell-cell interactions Journal of Cell Biology 110 803-815

Lee $\mathbf{E}$, Lotz M, Steele $\mathbf{G}$ and Mercurio A (1992) The integrin $\alpha_{6} \beta_{4}$ is a laminin receptor Journal of Cell Biology 117 671-679

Lockwood CJ, Senyei AE, Dische MR, Casal D, Shah KD, Thung SN, Jones L, Deligdisch $\mathbf{L}$ and Garite TJ (1991) Fetal fibronectin in cervical and vaginal secretions as a predictor of preterm delivery New England Journal of Medicine $325669-674$

Malak TM and Bell SC (1993) The structural characteristics of spontaneously ruptured fetal membranes: their relationship to membrane rupture and parturition Contemporary Reviews in Obstetrics and Gynaecology 5 117-123

Malak TM and Bell SC (1994) Distribution of fibrillin-containing microfibrils and elastin in human fetal membranes and decidua: a novel molecular basis for membrane elasticity American Journal of Obstetrics and Gynecology 171 195-205

Malak TM, Ockleford CD, Bell SC, Dalgleish R, Bright N and MacVicar J (1993) Confocal immunofluorescence localization of collagen types I, III, IV, V and VI and their ultrastructural organization in term human fetal membranes Placenta 14 385-406

Marchisio PC, Cancedda R and De LM (1990) Structural and functional studies of integrin receptors in cultured human keratinocytes Cell Differentiation and Development 32 355-359

Parry-Jones E and Priya S (1976) A study of the elasticity and tension of fetal membranes and of the relation of the area of the gestational sac to the area of the uterine cavity British Journal of Obstetrics and Gynaecology 83 205-212

Rosa J-P and McEver RP (1989) Processing and assembly of the integrin, glycoprotein IIb/IIla in HEL cells Jourmal of Biological Chemistry 264 12596-12603

Salafia CM, Weigl C and Silberman L (1989) The prevalence and distribution of acute placental inflammation in uncomplicated term pregnancies Obstetrics and Gynecology 73 383-389

Schmidt W (1992) The Amniotic Fluid Compartment: the Fetal Habitat SpringerVerlag, Berlin

Sonnenberg A, Janssen J, Hogervorst F, Calafat J and Hilgers J (1987) A complex of platelet glycoproteins Ic and Ila identified by a rat monoclonal antibody Journal of Biological Chemistry 262 10376-10383

Springer TA, Dustin ML, Kishimoto TK and Marlin S (1987) The lymphocyte function-associated LFA-1, CD2 and LFA-3 molecules: cell adhesion receptors of the immune system Annual Review of Immunology 5 223-252

Stepp MA, Spurr-Michaud S, Tisdale A, Elwell J and Gipson IK (1990) $\alpha_{6} / \beta_{4}$ Integrin heterodimer is a component of hemidesmosomes Proceedings of the National Academy of Sciences USA 87 8970-8974

Stepp M, Spurr M and Gipson I (1993) Integrins in wounded and unwounded stratified squamous epithelium of the cornea Investigative Ophthalmology and Visual Science 34 1829-1844

Wang $T$ and Schneider J (1983) Fine structure of human chorionic membrane: ultrastructural and histological examination Archives of Gynecology 233 187-198

White J, Amos W and Fordham M (1987) An evaluation of confocal versus conventional imaging of biological structures by fluorescence light microscopy Journal of Cell Biology 105 41-48

Yeh IT, O'Connor DM and Kurman RJ (1989) Vacuolated cytotrophoblast: a subpopulation of trophoblast in the chorion laeve Placenta $10429-438$

Ylanne J and Vitranen I (1989) The MR 140000 fibronectin receptor complex in normal and virus-transformed human fibroblasts and in fibrosarcoma cells; identical localization and function International Journal of Cancer $\mathbf{4 3}$ $1126-1236$

Ylanne J, Hormia M, Jarvinen M, Vartio T and Vitranen I (1988) Platelet glycoprotein Ilb/IIla complex in cultured cells. Localization in focal adhesion sites in spreading HEL cells Blood 72 1478-1486 